Revista de Derecho

Universidad Católica del Norte

Sección: Ensayos

Ańo 18 - No 1, 2011

pp. 241-226

\title{
EL ARBITRAJE DE CONSUMO COMO MEDIO \\ EXTRAJUDICIAL DE RESOLUCIÓN DE CONFLICTOS EN LA NORMATIVA ESPAÑOLA
}

\section{Diana Marcos Francisco*}

RESUMEN: El presente trabajo tiene por objeto el estudio del sistema arbitral de consumo español, en cuyo seno se incardinan distintas Alternative Dispute Resolution. En este sentido, se analiza tanto el arbitraje de consumo en sentido estricto, indicando su ámbito de aplicación y sus principales características, como la mediación y la conciliación, los otros medios extrajudiciales de resolución de conflictos que tienen lugar dentro del mismo procedimiento arbitral de consumo. Y todo ello a la luz de la normativa reguladora del sistema español de arbitraje de consumo y, especialmente, del reciente Real Decreto 231/2008, de 15 de febrero, regulador del Sistema Arbitral de Consumo.

PALABRAS CLAVE: Arbitraje - mediación - conciliación - consumidores o usuarios - empresarios o profesionales.

\section{THE ARBITRATION OF CONSUMPTION AS AN EXTRAJUDICIAL MEANS OF CONFLICT RESOLUTION IN THE SPANISH NORMATIVE SYSTEM}

ABSTRACT: This piece of work aims to study the arbitration system of consumption in Spain, where different Alternative Dispute Resolutions are incorporated. In this sense, not only the arbitration of consumption in a strict sense is analyzed indicating its field of application and its main characteristics, but also the mediation and the settlement, the other extrajudicial means of conflict resolution that take place within the same consumption arbitration procedure. And all of this under the light of the regulating norms of the Spanish system and, especially, of the recent Royal Decree 231/2008, of February 15, that regulates the Arbitration of Consumption System.

Doctora en Derecho Procesal. Profesora de la Universidad Católica de Valencia, subprograma Juan de la Cierva del Ministerio de Ciencia e Innovación. Correo electrónico: Diana. Marcos@uv.es

Fecha de recepción: 7 de octubre de 2010.

Fecha de aceptación: 15 de diciembre de 2010. 
KEY WORDS: Arbitration - mediation - conciliation - consumers or users - businesspersons or professional persons.

\section{INTRODUCCIÓN}

Las Alternativa Dispute Resolution (ADR) en materia de consumo han venido recibiendo desde hace décadas un gran impulso, incluso desde instancias comunitarias. A efectos de no excedernos de lo que es objeto del presente trabajo, nos limitaremos a recordar el Programa Preliminar de Acción para la Información y Protección de los Consumidores, de 14 de abril de 1975, aprobado por el Consejo de las (entonces) Comunidades Europeas (en adelante, CE) por Resolución de 14 de abril de 1975'; el Libro Verde de la Comisión sobre Acceso de los consumidores a la justicia y solución de litigios en materia de consumo en el Mercado Único, de 16 de noviembre de 1993; las destacadas Recomendación de la Comisión 98/257/CE, de 30 de marzo, relativa a los principios aplicables a los órganos responsables de la solución extrajudicial de los litigios en materia de consumo ${ }^{2}$ y la complementaria Recomendación de la Comisión, de 4 de abril de 2001, sobre los principios aplicables a los órganos extrajudiciales de resolución consensual de litigios en materia de consumo que no cubre la Recomendación 98/257/CE; y el Libro Verde sobre las modalidades alternativas de resolución de conflictos en el ámbito del derecho civil y mercantil, de 19 de abril de $2002^{3}$.

El arbitraje, la mediación y la conciliación son las ADR que han mostrado un especial interés en el ámbito del consumo. Nuestro Estado se decantaba y abogaba especialmente por la primera vía desde la "experiencia piloto" en la década de los ochenta del siglo pasado; postura que se ha reafirmado recientemente con la aprobación del Real Decreto 231/2008, de 15 de febrero, regulador del Sistema Arbitral de Consumo (en adelante, RD). Ello no significa que aquel haya descuidado las otras dos figuras, puesto que ha articulado un sistema arbitral de consumo en que ambas están presentes.

Así las cosas, el presente estudio tiene por objeto analizar la configuración de esta figura arbitral en Espańa como medio extrajudicial de resolución de conflictos de consumo, especialmente a la luz de la normativa

Diario Oficial de las Comunidades Europeas núm. C-92/16, de 25.4.75.

Diario Oficial de la Unión Europea (Serie L) núm. 115, de 17.4.1998.

Diario Oficial de la Unión Europea (Serie L) núm. 109, de 19.4.2001.

Para más detalles sobre el particular véase Barona VILAR, Silvia (2004). "ADR en materia de consumo en la Unión Europea”. En Ruiz Jiménez, José Ángel (coordinador): Temas actuales de consumo: la resolución de conflictos en materia de consumo. San Sebastián: Instituto Vasco de Derecho Procesal, pp. 63-95. 
estatal, dada la competencia exclusiva del Estado para su organización y establecimiento.

\section{FUENTES JURÍDICAS}

Para tratar las fuentes jurídicas sobre arbitraje de consumo, conviene distinguir entre las normas jurídicas estatales y aquellas otras dictadas por las Comunidades Autónomas.

\section{(1.1.) NORMATIVA ESTATAL}

Comenzando por el arbitraje de consumo (en lo sucesivo, AC) y, en concreto, por la regulación de carácter nacional, la normativa básica y principal sobre el mismo es el específico Real Decreto 231/2008, de 15 de febrero, regulador del Sistema Arbitral de Consumo (Boletín Oficial del Estado -en adelante, B.O.E.-, núm. 48, de 25 de febrero). A tal norma específica se ha de añadir, como legislación de aplicación supletoria, la Ley 60/2003, de 23 de diciembre, de Arbitraje (B.O.E., núm. 309, de 26 de diciembre); la Ley 30/1992, de 26 de noviembre, de Régimen Jurídico de las Administraciones Públicas y del Procedimiento Administrativo Común (B.O.E., núm. 285, de 27 de diciembre), de aplicación supletoria con respecto a la actividad de las juntas arbitrales de consumo (art. 3.2 RD); y la Ley 11/2007, de 22 de junio, de acceso electrónico de los ciudadanos a los servicios públicos (B.O.E., núm. 50, de 23 de junio), en relación con el arbitraje electrónico y actos realizados por vía electrónica (art. 3.3 RD).

El mencionado RD ha sido dictado en desarrollo de los arts. 57 y 58 del Texto Refundido de la Ley General de Defensa de los Consumidores y Usuarios y otras Leyes Complementarias (TR, en adelante), aprobado por el Real Decreto Legislativo 1/2007, de 16 de noviembre (B.O.E., núm. 287, de 30 de noviembre). Ambas normas, a su vez, han sido dictadas en cumplimiento de lo dispuesto, respectivamente, en la Disposición Final Sexta y Quinta de la Ley 44/2006, de 29 de diciembre, de Mejora de la Protección de los Consumidores y Usuarios (B.O.E., núm. 312, de 30 de diciembre). Y ello sin perjuicio de que, en última instancia, se fundamenten en el art. 51 de la Constitución española y de que de la Disposición Adicional Única de la Ley 60/2003 (en lo sucesivo, LA), de Arbitraje (B.O.E., núm. 309, de 26 de diciembre) ya se intuyera una nueva y posible regulación futura del $\mathrm{AC}^{4}$.

4 Como muy bien apuntaba Palao Moreno al tratar esta Disposición dedicada a los "arbitrajes de consumo", la fórmula empleada en su redacción "nos puede llevar a pensar que, o 


\section{(1.2.) NORMATIVA AUTONÓMICA}

Junto a tal normativa estatal, en cumplimiento de la misma y también considerando la competencia en materia de consumo asumida por las Comunidades Autónomas en virtud de sus respectivos Estatutos o leyes orgánicas de trasferencia de competencias de titularidad estatal ${ }^{5}$, existe numerosa normativa de carácter autonómico, de muy distinta índole y rango, sobre el sistema arbitral de consumo.

Así, se ha de hacer mención, por un lado, de las distintas leyes generales autonómicas de protección de los consumidores y usuarios que contienen referencias a la institución arbitral en sede de consumo, a saber:

1) Arts. 15, 20.3.b), 93.1.b), 97.1.c), 98.1.c), 99.2.e) e i) de la Ley 13/2003, de 17 de diciembre, de Defensa y Protección de los Consumidores y Usuarios de Andalucía (Boletín Oficial -en adelante, B.O.- de la Junta de Andalucía, núm. 251, de 31 de diciembre y B.O.E., núm. 14, de 16 enero 2004);

2) Arts. 21, 22, 23, 29.c) y j), 42, 64.3 y 5 y $77 . g$ ) y h) de la Ley 16/2006, de 28 de diciembre, de Protección y Defensa de los Consumidores y Usuarios de Aragón (B.O. Aragón núm. 149, de 30 de diciembre y B.O.E., núm. 45, de 21 de febrero de 2007);

3) Arts. 21.1.c) y 2, 25.e) y 28 de la Ley del Principado de Asturias $11 / 2002$, de 2 de diciembre, de los Consumidores y Usuarios (B.O. del Principado de Asturias, núm. 287, de 13 de diciembre y B.O.E., núm. 13, de 15 de enero de 2003);

4) Arts. 24.1.c), 27.c), 30, 31, 33.1.c) y 56.2 de la Ley $1 / 1998$, de 10 de marzo, del Estatuto de los Consumidores y Usuarios de la Comunidad Autónoma de las Islas Baleares (B.O. Illes Balears núm. 37, de 17 de marzo y B.O.E., núm. 113, de 12 de mayo);

5) Arts. 16.3, 21.1.c), 25 y 45.3.h) de la Ley 3/2003, de 12 de febrero, del Estatuto de los Consumidores y Usuarios de la Comunidad Autónoma de Canarias (B. O. Canarias, núm. 34, de 19 de febrero, y B.O.E., núm. 56, de 6 de marzo);

bien desea emplear una expresión suficientemente genérica que permita futuros desarrollos normativos, o bien que el legislador esté precisamente considerando acometer tales cambios y no desee mencionar de modo concreto el Real Decreto de 1993" (Palao Moreno, Guillermo (2004). "Comentario a la Disposición Adicional Única. Arbitrajes de consumo". En Barona Vilar, Silvia (coordinadora): Comentarios a la Ley de Arbitraje (Ley 60/2003, de 23 de diciembre), Thomson-Civitas, pp. 1621-1640, p. 1625).

5 Y sea esta exclusiva o plena-limitada, de desarrollo legislativo o ejecutiva. Sobre el particular, y para más detalle, véase Guillén Caramés, Javier, (2007). "Las competencias de los diferentes entes territoriales en materia de protección de los consumidores". En Parada Vázquez, Ramón y Fernández Rodríguez, Carmen (directores): Las competencias locales, Marcial Pons, pp. 347-398, especialmente, pp. 356-363. 
6) Arts. 13, 17.4.c), 27.2.b), 28.1.h) 32.2.d), 40.5 y 50.2.p) de la Ley de Cantabria 1/2006, de 7 de marzo, de Defensa de los Consumidores y Usuarios (B.O. Cantabria, núm. 52, de 15 de marzo y B.O.E., núm. 77 , de 31 de marzo);

7) Arts. 14, 16.2.b) y k) y 19.4.c) de la Ley $11 / 2005$, de 15 de diciembre, del Estatuto del Consumidor de Castilla-La Mancha (D.O. Castilla-La Mancha, núm. 255, de 20 de diciembre y B.O.E., núm. 46, de 23 de febrero 2006);

8) Arts. 16.2, 22 y 40.2.d) y e) de la Ley 11/1998, de 5 de diciembre, para la Defensa de los Consumidores y Usuarios de Castilla y León (B.O. Castilla y León, núm. 236, de 10 de diciembre, rect. B.O. Castilla y León, núm. 51, de 16 de marzo, y B.O.E., núm. 16, de 19 de enero de 1999);

9) Arts. 19.3 y 20 de la Ley 3/1993, de 5 de marzo, del Estatuto del Consumidor de Cataluña (DO. Generalitat de Catalunya, núm. 1718, de 12 de marzo y B.O.E., núm. 81, de 5 de abril);

10) Art. 21.f) de la Ley 6/2001, de 24 de mayo, del Estatuto de los Consumidores de Extremadura (D.O. Extremadura, núm. 72, de 23 de junio y B.O.E., núm. 173, de 20 de julio);

11) Arts. 16.3, 25.e), 27.a), 31, 57.1, 62.2.i) y 63.1.f) de la Ley 11/1998, de 9 de julio, de Protección de los Consumidores de la Comunidad de Madrid (B.O. Comunidad de Madrid, núm. 167, de 16 de julio, rect. B.O. Comunidad de Madrid, núm. 178, de 29 de julio y B.O. Comunidad de Madrid, núm. 298, de 16 de diciembre y B.O.E., núm. 206, de 28 de agosto);

12) Art. 20.5 y 7 de la Ley 4/1996, de 14 de junio, del Estatuto de los Consumidores y Usuarios de la Región de Murcia, modificada por la Ley 1/2008, de 21 de abril (B.O. Región de Murcia, núm. 146, de 25 de junio y B.O.E., núm. 238, de 2 de octubre);

13) Arts. 17.c) y f), 21.1, 37 y 39.1) de la Ley Foral 7/2006, de 20 de junio, de Defensa de los Consumidores y Usuarios de Navarra (B.O. Navarra, núm. 78, de 30 de junio y B.O.E., núm. 172, de 20 de julio);

14) Arts. 13, 21.i), 32.e), 34.a), 66.2.i) y 68.1.f) de la Ley 6/2003, de 22 de diciembre, de Estatuto de las Personas Consumidoras y Usuarias del País Vasco (B.O. País Vasco, núm. 254, de 30 de diciembre);

15) Arts. $14,2^{\circ}$. c), 16, 28.d) y j), 31, 33.5 y 9 de la Ley $2 / 1987$, de 9 de abril, de Estatuto de Consumidores y Usuarios de la Comunidad Valenciana (D.O. Generalitat Valenciana, núm. 568, de 15 de abril y B.O.E., núm. 102, de 29 de abril 1987).

Téngase en cuenta, por un lado, la excepcional referencia al arbitraje contenida en el arts. 49.2 del Estatuto de Autonomía de Cataluña de 2006, aprobado por LO 6/2006, de 19 julio (B.O.E., núm. 172, de 20 
de julio); y, por otro, que no nos hemos referido a la Ley 12/1984, de 28 de diciembre, del Estatuto Gallego del Consumidor y Usuario (D.O. Galicia, núm. 23, de 1 de febrero de 1985 y B.O.E., núm. 139, de 11 de junio) considerando que el párrafo $2^{\circ}$ de su art. 31 , que atribuía funciones de arbitraje en materia de consumo a la comisión consultiva gallega que el mismo precepto creaba en su primer párrafo, fue declarado inconstitucional por la Sentencia del Tribunal Constitucional (Pleno) 62/1991, de 22 de marzo.

Por otro lado, hay que mencionar los convenios de colaboración suscritos entre el Instituto Nacional del Consumo y las respectivas Administraciones autonómicas para la constitución de las distintas juntas arbitrales autonómicas de consumo (que, de conformidad con lo dispuesto en la Disposición Transitoria Primera del RD 231/2008, se encuentran en periodo de adaptación a tal RD hasta el 25 de agosto de 2010). En concreto, son los siguientes:

1) Acuerdo de 3 de diciembre de 1993 para la constitución de la Junta Arbitral de Consumo Autonómica de Andalucía (publicada por Resolución de 27 de diciembre de 1993, de la Dirección General de la Alta Inspección y Relaciones Institucionales, B.O.E., núm. 21, de 25 de enero de 1994);

2) Acuerdo suscrito con fecha de 15 de julio de 1994 para la constitución de la Junta Arbitral de Consumo de la Comunidad Autónoma de Aragón (Resolución de 22 julio 1994 de la Dirección General de la Alta Inspección y Relaciones Institucionales, B.O.E., núm. 189, de 9 de agosto). Por Orden de 5 de agosto de 1994 del Departamento de la Presidencia y Relaciones Institucionales se ordena la publicación de tal Convenio en el B.O. Aragón, núm. 103, de 29 de agosto;

3) Acuerdo de 16 de marzo de 1994 para la constitución de la Junta Arbitral de Consumo autonómica de Asturias (publicada por Resolución de 29 de marzo de 1994, de la Dirección General de la Alta Inspección y Relaciones Institucionales, B.O.E., núm. 90, de 15 de abril);

4) Acuerdo de 22 de abril de 1994 para la constitución de la Junta Arbitral de Consumo Autonómica de Las Islas Baleares (publicada por Resolución de 26 de abril de 1994, de la Conselleria de Sanidad y Seguridad Social, B.O. Illes Balears, núm. 73, de 16 de junio; y por Resolución de 12 de mayo de 1994, de la Dirección General de la Alta Inspección y Relaciones Institucionales, en el B.O.E., núm. 129 , de 31 de mayo);

5) Acuerdo de 11 de julio de 1994 de constitución de la Junta Arbitral de Consumo de Canarias (publicado por Resolución de 20 de julio de 1994, de la Dirección General de la Alta Inspección y Relaciones Institucionales, B.O.E., núm. 186, de 5 de agosto, y por Orden 
de 18 octubre 1994 de la Consejería de Industria y Comercio en el B.O. Canarias, núm. 130, de 24 de octubre);

6) Acuerdo de 30 de diciembre de 1996 para la constitución de la Junta Arbitral de Consumo de la Comunidad Autónoma uniprovincial de Cantabria (publicado por Resolución de la Subsecretaría del Ministerio de Sanidad y Consumo de 20.5.1997, B.O.E., núm. 143, de 16 de junio de 1997).

7) Acuerdo de 12 de abril de 1994 para la constitución de la Junta Arbitral de Consumo de la Comunidad Autónoma de Castilla-La Mancha (publicado por Resolución de la Dirección General de la Alta Inspección y Relaciones Institucionales de 17.5.1994, B.O.E., núm. 131 , de 2 de junio).

8) Acuerdo de 19 abril 1994 para la constitución de la Junta Arbitral de Consumo de Castilla y León (Resolución de 3 de mayo de 1994, del Instituto Nacional de Consumo, publicado en el B.O.E., núm. 121, de 21 de mayo, y en el BO. Castilla y León, núm. 86, de 5 de mayo);

9) Acuerdo de 6 de mayo de 1993 para la constitución de la Junta Arbitral de Consumo de Cataluña (es característica de este acuerdo el no figurar los datos sobre su publicación en el B.O.E. en los repertorios al uso);

10) Acuerdo de 6 de mayo de 1994 para la constitución de la Junta Arbitral de Consumo de la Comunidad Autónoma de Extremadura (publicado por Resolución ed 13 de mayo de 1994 de la Consejería de la Presidencia y Trabajo, D.O. Extremadura, núm. 58, de 21 de mayo; y por Resolución de la Dirección General de la Alta Inspección y Relaciones Institucionales de 20.5.1994, B.O.E., núm. 136, de 8 de junio);

11) Acuerdo de 5 de julio de 1994 para la constitución de la Junta Arbitral de Consumo autonómica de Galicia (publicado por Resolución de 11 de julio de 1994, de la Dirección General de la Alta Inspección y Relaciones Institucionales, B.O.E., núm. 177, de 26 de julio; y por Resolución de 8 de julio de 1994 de la Consejería de Industria y Comercio, en el D.O. Galicia, núm. 141, de 22 de julio);

12) Acuerdo de 14 de febrero de 1994 para la constitución de la Junta Arbitral de Consumo autonómica de La Rioja (publicado por Resolución de 29 de marzo de 1994, de la Dirección General de la Alta Inspección y Relaciones Institucionales, B.O.E., núm. 90, de 15 de abril);

13) Acuerdo de 5 de noviembre de 1997 para la constitución de la Junta Arbitral de Consumo autonómica de Madrid (publicado por Resolución de 14 de enero de 1998 de la Subsecretaría, B.O.E., núm. 38, de 13 de febrero de 1998);

14) Acuerdo de 10 de noviembre de 1993 para la constitución de la Junta Arbitral de Consumo de la Región de Murcia (Resolución de 20 
de diciembre de 1993, de la Consejería de Sanidad y Asuntos Sociales, B.O. Región de Murcia, núm. 2, de 4 de enero de 1994);

15) Acuerdo de 17 de junio de 1993 para la constitución de la Junta Arbitral de Consumo autonómica de Navarra (publicado por Resolución de 7 de octubre de 1993, de la Dirección General de la Alta Inspección y Relaciones Institucionales, B.O.E., núm. 255, de 25 de octubre);

16) Acuerdo de 14 de marzo de 1994 para la constitución de la Junta Arbitral de Consumo autonómica del País Vasco (publicado por Resolución de 29 de marzo de 1994, de la Dirección General de la Alta Inspección y Relaciones Institucionales, B.O.E., núm. 90, de 15 de abril);

17) Acuerdo de 4 de noviembre de 1993 para la constitución de la Junta Arbitral de Consumo autonómica de Valencia (publicado por Resolución de 5 de abril de 1994, de la Conselleria de Sanidad y Consumo, D.O. Generalitat Valenciana, núm. 2252, de 25 de abril de 1994);

Téngase en cuenta que hemos mencionado los acuerdos de constitución suscritos de conformidad o adaptados a lo dispuesto en el ya derogado RD 636/1993, de 3 de mayo, regulador del Sistema Arbitral de Consumo, primera norma estatal en esta materia. Pero hay que advertir que algunas Comunidades Autónomas, con anterioridad a su entrada en vigor, ya habían constituido sus correspondientes juntas arbitrales durante la "experiencia piloto" (en concreto, Murcia, Asturias, Castilla-La Mancha y Madrid).

Y, por último, existen numerosos decretos, órdenes, resoluciones o normas de otro tipo en este ámbito autonómico reguladores del sistema arbitral de consumo ${ }^{6}$.

En cualquier caso, se ha de tener muy presente que, como ha reiterado el Tribunal Constitucional, el establecimiento y organización de dicho sistema es competencia exclusiva del Estado con base en el art. 140.1, 5 y 6 de la Constitución Española vigente de 1978 (véase, por ejemplo, la Sentencia del Tribunal Constitucional núm. 15/1989 -Pleno-, de 26 de enero), al ser el arbitraje un "equivalente jurisdiccional" (Sentencia del Tribunal Constitucional núm. 62/1991 -Pleno-, de 22 de marzo). De ahí,

6 Además de las citadas, las normas autonómicas más importantes sobre el particular, incluyendo algunas excepcionales de rango legal, se recogen en el Anexo de este trabajo, clasificadas por orden alfabético de las distintas Comunidades Autónomas y, dentro de estas, por orden cronológico. 
por una parte, que la norma básica reguladora de todo arbitraje de consumo y a la que principalmente hemos de estar es el repetido y reciente $\mathrm{RD}$ de 2008. Y de ahí, por otra, que resulte criticable la regulación de algunas Comunidades Autónomas que, invadiendo competencias estatales, se han extralimitado en sus funciones dictando normas que, más allá de ser un mero desarrollo del RD estatal regulador del AC y de los citados convenios y más allá de ser normas de cumplimiento de los mismos para hacerlos efectivos (p. ej., las relativas a la adscripción de las respectivas juntas arbitrales a los concretos servicios administrativos, a las bases reguladoras de la concesión de subvenciones para el funcionamiento y equipamiento de las Juntas arbitrales o fomento de sus actividades, al nombramiento de los presidentes y secretarios de la junta arbitral o sobre las dietas que han de percibir los árbitros por integrar los órganos arbitrales y asistir a las sesiones), constituyen auténticas aportaciones en la creación o establecimiento de un sistema arbitral o arbitraje de consumo ${ }^{7}$.

\section{CONCEPTO, SUJETOS Y OBJETO}

\section{(2.1.) CONCEPTO}

De conformidad con lo dispuesto en el mencionado TR (especialmente, en su art. 57.1), y en el citado Real Decreto 231/2008 (en especial, en su art. 1.2), el arbitraje de consumo puede definirse como el medio extrajudicial de resolución de conflictos de derecho privado de consumo entre empresarios o profesionales y consumidores o usuarios,

Rodríguez Rodríguez, José Luis (2006). Origen, estructura y funcionamiento de las juntas arbitrales de consumo. 1 ${ }^{\text {a }}$ Edición. San Sebastián: Instituto Vasco de Derecho Procesal, 608 pp., especialmente, pp. 300 y 301.

A modo de ejemplo, véanse los arts. 2 a 5 del Decreto 212/1994, de 25 de octubre; los arts. 3 y 4 y la Disposición Final Primera del Decreto 37/1999, de 18 marzo; los arts. 1 a 7 del Decreto 104/2002, de 22 de agosto; los arts. 1, 3, 4, 6 y 13 del Decreto 44/1995, de 9 mayo; el art. 6.1 y 4 del Decreto 242/2005, de 8 de noviembre; el art. 12 del Decreto 329/1995, de 21 de diciembre y el art. 6 del Decreto 192/2005, de 23 de junio, en virtud de los cuales el Instituto Gallego de Consumo asume funciones correspondientes a la propia junta arbitral autonómica; y el art. 5 del Decreto 246/2001, de 18 de octubre. Para más detalles sobre tales extralimitaciones, véanse las pp. 300 a 338 de igual obra del autor citado.

Repárese, asimismo, que también existen convenios de constitución de las juntas arbitrales de consumo de distinto ámbito territorial al autonómico (tanto los relativos a las Ciudades Autónomas de Ceuta y Melilla -véase el Anexo- como los de ámbito inferior: provincial, de mancomunidad de municipios y municipales), así como algunas normas de desarrollo del sistema arbitral de consumo emanadas de estas Administraciones locales que cuentan con su propia junta arbitral. 
regulado singularmente por el repetido $\mathrm{RD}$, al que los mismos se someten voluntariamente y en virtud del cual un órgano arbitral designado al efecto por la junta arbitral de consumo competente decide la controversia a través de una resolución firme (denominada laudo) que, como las sentencias judiciales, es título ejecutivo (art. 517.2. ${ }^{\circ}$ de la Ley de Enjuiciamiento Civil $1 / 2000$, de 7 de enero) y goza de igual fuerza o eficacia de cosa juzgada (art. 43 de la LA).

Así se concibe en teoría el arbitraje de consumo. Y, en la práctica, estamos ante un sistema arbitral de consumo que, tal y como demuestran las distintas Memorias anuales elaboradas por el Instituto Nacional de Consumo sobre la materia, ha alcanzado un gran éxito ${ }^{8}$ y constituye el prototipo de arbitraje institucional en España?

\section{(2.2.) Sujetos}

El Real Decreto nada dice sobre los conceptos de consumidor o usuario y empresario o profesional a sus efectos. Pese a ello, en la medida en que el AC por él regulado encuentra su origen en el art. 57.2 TR, es lógico entender que en principio el concepto de consumidor o usuario contemplado o definido por el art. $3 \mathrm{TR}$ a sus efectos es el que debe regir también a los del AC (Sentencia de la Audiencia Provincial -en lo sucesivo, SAP- de Madrid núm. 122/2004 -Sección 12a-, de 16 de febrero), esto es, "las personas físicas o jurídicas que actúan en un ámbito ajeno a una

8 Considerando las Memorias anuales más recientes del Instituto Nacional de Consumo sobre el sistema arbitral de consumo, una prueba de esta eficacia general del sistema arbitral de consumo viene constituida por la totalidad de solicitudes resueltas desde 2003 a 2007 con respecto a las presentadas, pudiendo tenerse una visión general de ascenso en ambas que ha hecho posible una adaptación del sistema a situaciones de práctica saturación (véanse las pp. 10 y 11 de la Memoria de 2007, accesible actualmente en http://www.consumo-inc.es/Arbitraje/docs/memarb072.pdf). Por otro lado, cabe reseńar que cada vez son más las empresas adheridas a este sistema, figurando ya 141.410 en el 2007 (véase la p. 26 de la repetida Memoria de 2007 arriba citada, precisando que "durante este periodo el número de empresas que se adhirieron fue de 8.338" -véase, asimismo, la Tabla 10, sobre el "total de adhesiones, nuevas adhesiones y denuncias de ofertas públicas de sometimiento"-) frente a las 140.651 del año 2006 (p. 31 del Resumen Memoria 2005-2006 del Sistema Arbitral de Consumo del Instituto Nacional del Consumo, disponible a fecha de hoy en http://www.consumoinc.es/Arbitraje/docs/arbitraje0506.doc, donde puede encontrarse el número de empresas adheridas y su incremento desde 1999 hasta el 2006), una prueba más del auge del sistema arbitral de consumo.

9 Casado Cerviño, Alberto (2006). "El arbitraje de consumo". Actualidad Civil, No 4, pp. 389-430. Disponible en: http://authn.laley.net/comun/cgi-bin/imprimir_actualidad. pl?http://authn.laley.net/ra_civic/2006/r04c_2006_af_1.html [fecha de visita 3 de enero de 2007], p. 1. 
actividad empresarial o profesional"10. De ello se desprende un concepto de consumidor o usuario como destinatario final ${ }^{11}$.

Y lo mismo cabe decir con respecto al concepto de empresario recogido en el art. $4 \mathrm{TR}^{12}$, entendido como "toda persona física o jurídica que actúa en el marco de su actividad empresarial o profesional, ya sea pública o privada"; concepto que se encuentra en la línea del más reciente concepto en el ámbito comunitario de "comerciante"13. Por lo tanto, ya no hay duda de que se excluyen de su ámbito de aplicación las relaciones entre particulares, literalmente englobadas en la anterior definición de la LGDCU ${ }^{14}$ y que habían originado no pocos problemas en la práctica del consumo, incluso arbitral ${ }^{15}$.

10 El apartado II de la Exposición de Motivos de dicho Texto ya adelanta que incorpora en su Libro I una lista de conceptos que asegura "una mayor claridad en la redacción, evitando repeticiones innecesarias e integrando las lagunas que había identificado la doctrina”; y, por si cupiera alguna duda, el apartado III ańade que, aunque se ha acogido un concepto de consumidor adaptado al propio de la normativa comunitaria (verdaderamente es este el concepto de consumidor que se viene imponiendo en el ámbito comunitario. Baste citar la Directiva 1999/44/CE, del Parlamento y del Consejo, de 25 de mayo de 1999, sobre determinados aspectos de la venta y las garantías de los bienes de consumo; la Directiva 1998/6/CE, del Parlamento y del Consejo, de 16 de febrero, sobre protección de los consumidores en materia de indicación de precios de los productos ofrecidos a los consumidores; Directiva 2005/29/CE, del Parlamento Europeo y del Consejo, de 11 de mayo de 2005, relativa a las prácticas comerciales desleales de las empresas en sus relaciones con los consumidores en el mercado interior; y la reciente Propuesta de Directiva sobre derechos de los consumidores, de 8.10.2008, según la que es consumidor "toda persona física que, en contratos regulados por la presente Directiva, actúe con un propósito ajeno a su actividad comercial, empresa, oficio o profesión" -art. 2.1-), se han respetado las peculiaridades de nuestro ordenamiento con respecto a las personas jurídicas, de forma que "el consumidor y usuario, definido en la ley, es la persona física o jurídica que actúa en un ámbito ajeno a una actividad empresarial o profesional. Esto es, que interviene en las relaciones de consumo con fines privados, contratando bienes y servicios como destinatario final, sin incorporarlos, ni directa, ni indirectamente, en procesos de producción, comercialización o prestación a terceros".

11 Bercovitz Rodríguez-Cano, Alberto (2008). "La experiencia del arbitraje de consumo". En Tomillo Urbina, Jorge (director) y Álvarez Rubio, Julio (coordinador): El futuro de la protección jurídica de los consumidores. (Actas del I Congreso Euroamericano de Protección Jurídica de los Consumidores, Cizur Menor (Navarra): Aranzadi, pp. 379-388, p. 383.

12 Resulta llamativo que el TR, a efectos simplificativos, haya omitido y prescinda del término "profesional", aludiendo únicamente al "empresario" (mientras que el RD se ha referido y ha utilizado expresamente ambos términos a lo largo de su articulado) y, sin embargo, no haya aprovechado la ocasión para "deshacerse de los usuarios", en coherencia, por otra parte, con el Derecho comparado (véase Cabanillas Múgica, S., (2008). "El Real Decreto Legislativo 1/2007, por el que se aprueba el texto refundido de la Ley General para la Defensa de los Consumidores y Usuarios y otras leyes complementarias". Aranzadi Civil, No 1. Disponible en: www.westlaw.es [fecha de visita junio de 2008], p. 5).

13 Así, el art. 2.2) de la mencionada y reciente Propuesta de Directiva sobre derechos de los consumidores, lo define como "toda persona física o jurídica que, en contratos regulados por la presente Directiva, actúe con un propósito relacionado con su actividad comercial, empresa, oficio o profesión (...)".

14 Cabanillas Múgica (2008) 4.

15 Y es que la derogada Ley 26/1984, de 19 de julio, General de Defensa de los Consumidores y Usuarios guardaba silencio sobre los empresarios, como parte, junto al consumidor o 
Conviene precisar en relación con los sujetos que es irrelevante el carácter de la forma jurídica que adopte el concepto de empresario (esto es, si es persona física o jurídica y, en este último caso, sociedad mercantil anónima o limitada), su carácter público o privado. La condición de empresario a efectos del AC puede ser ostentada tanto por un sujeto privado como público, de forma que también las empresas o entidades públicas que actúan en régimen de Derecho privado están legitimadas pasivamente para intervenir en un AC.

Así se desprende, por un lado, del art. 20.1 RD, al regular la composición y designación de los árbitros en aquellos casos en que "la reclamación se dirija contra una entidad pública vinculada a la Administración a la que esté adscrita la junta arbitral de consumo" (en similares términos se pronunciaba el art. 11.1.a), párrafo $3^{\circ}$, del RD de $1993^{16}$ ). Por otro, también se desprende del art. 32.1 del nuevo RD ya que, si no, no se entendería que en este precepto se prevea que "las Administraciones públicas instarán a las empresas o entidades pertenecientes al sector público o a las concesionarias que comercialicen bienes o servicios destinados a consumidores o usuarios en régimen de derecho privado, a presentar oferta pública de adhesión al sistema arbitral de consumo" 17 . Y, en tercer lugar, también lo ha

usuario, de la relación jurídica de consumo. Silencio que también guardaba el anterior RD 636/1993 (aunque verdaderamente de sus arts. 4.a) y c), 7.2 y 4 y 11.1.c) cabía deducir que los sujetos legitimados pasivamente eran los empresarios o profesionales) y que ha conducido a que las distintas juntas arbitrales de consumo no hayan venido siguiendo un criterio uniforme, admitiendo que incluso un particular pudiera ser reclamado vía AC para resolver los problemas derivados de arrendamientos de viviendas.

16 Tal precepto hablaba de "si la reclamación se dirige contra una entidad pública vinculada a la Administración pública de la que dependa la junta arbitral”.

17 Como ya bien decían Merino Merchán y Chillón Medina, las controversias derivadas de "las relaciones jurídicas consistentes en la prestación de un servicio público cuya utilización por los usuarios requiera el abono de una tarifa, tasa o precio público de aplicación general", excluidas del ámbito de aplicación de la derogada Ley 13/1996, de 18 de mayo, de Contratos de las Administraciones Públicas (art. 3.1.6, y art. 4.1.b) de la vigente y citada Ley de Contratos del Servicio Público) "son susceptibles de ser sometidas a arbitraje, excepto la aplicación de la propia tasa o del precio público por su carácter indisponible de acuerdo con su Ley reguladora y su determinación cuantitativa que es de aplicación y observancia general, aun cuando sí puede ser objeto de convenio arbitral su forma de pago". (Véase Chillón Medina, José Ma y Merino Merchán, José Fernando (1991). Tratado de arbitraje privado interno e internacional, Madrid, 653 pp., p. 311 . Cosa distinta es que se pretenda dirigir una reclamación contra una Administración Pública (por ejemplo, un Ayuntamiento) que ha actuado en régimen de Derecho público (ejercitando potestades administrativas) y que esta se someta a AC en calidad de demandada. Aunque se haya defendido lo contrario, considerando que corresponde a las Administraciones Públicas, principales prestadores de servicios, predicar con el ejemplo y someterse al sistema arbitral de consumo (Díaz Alabart, Silvia (1994). "El arbitraje de consumo (RD 636/1993, de 3 de mayo)". Estudios sobre Consumo, pp. 170-225, p. 212, nota 49; siguiéndola, RuIZ JiMÉNEZ, José Ángel (2007). Análisis critico del sistema nacional español de arbitraje de consumo, San Sebastián: Instituto Vasco de Derecho Procesal, 479 pp., p. 295), lo correcto es distinguir entre si los servicios que ofrece la Administración se prestan en régimen de derecho privado o público, de modo que en este último caso no cabría la posibilidad de sometimiento a arbitraje de 
entendido así la propia jurisprudencia menor (SAP Tarragona -Sección $3^{a}-$ núm. 234/2009, de 9 de julio ${ }^{18}$ ), aunque también es cierto que en la misma existen criterios discrepantes (véase la SAP Santa Cruz de Tenerife -Sección $1^{\text {a }}$ - núm. 320/2009, de 22 de junio) ${ }^{19}$.

\section{(2.3.) OBJETO O MATERIAS SUSCEPTIBLES DE ARBITRAJE DE CONSUMO}

No todo conflicto entre consumidores o usuarios y empresarios o profesionales es susceptible de someterse a la estudiada vía. Así, además de versar sobre "los derechos legal o contractualmente reconocidos al consumidor" (art. 1.2 RD), en coherencia con el art. 2.1 LA, es imprescindible "que versen sobre materias de libre disposición de las partes conforme a dere-

consumo (CAsas Valles, Ramón (1992): “Comentario al art. 31”. En Bercovitz RodríguezCano, Alberto y Salas Hernández, Javier (coordinadores): Comentarios a la Ley General para la Defensa de los Consumidores y Usuarios. Madrid: Civitas, pp. 763-809, p. 781, nota 55 in fine; Cuñat Edó, Vicente (1995): "Las juntas arbitrales de consumo". En AA.VV.: Perspectiva jurídica del arbitraje de consumo: Actas del Seminario "Arbitraje de consumo" (Valencia), Valencia: Generalitat Valenciana, Conselleria de Sanitat i Consum, 201 pp., p. 28; Gaspar Lera, Silvia (1998). El ámbito de aplicación del arbitraje. Pamplona: Aranzadi, 315 pp., p. 263; en la misma línea, Álvarez Alacón, aunque circunscribiendo la cuestión al carácter transigible -o disponible- o no de la controversia según la normativa aplicable. Véase Álvarez Alacón, Arturo (1999). El sistema español de arbitraje de consumo. Madrid: Instituto Nacional del Consumo, 254 pp., pp. 104 y 105). Y es que existen normas como el art. 7.3 de la Ley General Presupuestaria vigente (Ley 47/2003, de 26 de noviembre), que en principio hace inviable la estudiada posibilidad, salvo que el sometimiento a arbitraje se produzca por acuerdo del Consejo de Ministros (o Consejo de Gobierno de la Comunidad Autónoma) y dictamen favorable del Consejo de Estado (u órgano homólogo consultivo de la Comunidad Autónoma si lo hubiere) (véase Abellán Tolosa, Luis (2005). "El sistema arbitral de consumo”. En Reyes López, Ma José (coordinadora): Derecho privado de consumo. Valencia: Tirant lo Blanch, pp. 575-668, p. 609).

18 Apunta la misma que "si bien este Tribunal reconoce a la recurrente como una entidad de derecho público, sujeta a las previsiones de la Ley sobre Organización y Funcionamiento de la Administración General del Estado, ello no es obstáculo para que una materia como la que es objeto de controversia pueda ser sometida a una junta arbitral, pues nada impide que un usuario y Renfe Operadora puedan someter a arbitraje su discrepancia en orden a la procedencia o no de que esta debe indemnizarse por el retraso en la llegada de un determinado tren, en tanto que de materia negocial y, en definitiva, de libre disposición debe calificarse una pretensión indemnizatoria como la que nos ocupa" (Fundamento Jurídico Segundo). Se trata de términos que reproducen literalmente lo que ya pergeñaban sentencias anteriores de igual Sección de la AP de Tarragona, tales como la núm. 161/2009, de 14 de mayo, Fundamento Jurídico Segundo; núm. 163/2009, de 14 de mayo, Fundamento Jurídico Segundo; y núm. 170/2009, de 14 de mayo, Fundamento Jurídico Segundo.

19 Esta, con respecto a una reclamación similar a las anteriores (una pretensión indemnizatoria por los daños económicos - pérdida del vuelo posterior- derivados de una prestación defectuosa - por retraso- del servicio de la reclamada), partiendo de la naturaleza de entidad pública de la reclamada RENFE-Operadora, de lo dispuesto en los arts. 9.4 y 6 de la Ley 6/1985, de 1 de julio, del Poder Judicial; en el art. 2.2 de la citada Ley 30/1992, de 26 de noviembre; y en el art. 2.e) de la Ley 29/1998, de 13 de julio, reguladora de la Jurisdicción Contencioso-Administrativa, concluye que estamos ante una cuestión no susceptible de arbitraje ex art. 41.1.e) LA (Fundamento de Derecho Segundo). 
cho" (art. 2.1 RD). Por otro lado, se excluyen expresamente del aludido ámbito u objeto del AC "los conflictos que versen sobre intoxicación, lesión, muerte o aquellos en que existan indicios racionales de delito, incluida la responsabilidad por daños y perjuicios directamente derivada de ellos, conforme a lo previsto en el artículo 57.1"TR (art. 2.2 RD).

\section{CARACTERÍSTICAS PRINCIPALES}

Tal y como dice la Exposición de Motivos del propio RD, "este Reglamento mantiene las características esenciales del arbitraje de consumo". Siendo esto así en principio, la verdad es que la nueva regulación ha introducido novedades importantes. Veamos cuáles son los principales rasgos de tal institución.

\section{(3.1.) VOLUNTARIEDAD}

Las partes deben manifestar su voluntad de someterse a AC por expreso y de forma escrita, si bien este último requisito ha pasado a interpretarse en sentido amplio ${ }^{20}$, de acuerdo con lo previsto en el art. 9.3.2 ${ }^{\circ}$ LA, entendiéndose cumplido cuando el convenio arbitral haya sido pactado en cualquier forma o soporte que permita tener constancia del mismo y sea susceptible de reproducción (arts. 58.1 TR y 24.1.2० RD). En íntima relación, el mismo RD permite, por una parte, que las empresas o profesionales formulen "por escrito, por vía electrónica a través del procedimiento previsto en el capítulo V, sección I, o en cualquier otro soporte que permita tener constancia de la presentación y de su autenticidad, una oferta unilateral de adhesión al Sistema Arbitral de Consumo que tendrá carácter público" (art. 25.1.1); y, por otra, que los consumidores y usuarios presenten "por escrito, por vía electrónica a través del procedimiento previsto en el capitulo $V$, sección $I$, o por cualquier otro medio que permita tener constancia de la solicitud y de su autenticidad, la solicitud de arbitraje" (art. 34.1). Y, aunque el RD haya guardado silencio, no cabe duda de que iguales medios podrán ser utilizados por el empresario o profesional no adherido que acepte o rechace el sometimiento a un concreto $\mathrm{AC}^{21}$, como sí posibilitaba expresamente el art. 9.1 del anterior RD 636/1993.

20 Marín López, Manuel Jesús (2008). "La nueva regulación del arbitraje de consumo: el Real Decreto 231/2008, de 15 de febrero”. Diario La Ley, núm. 6905. Disponible en: diariolaley.es [fecha de visita junio de 2008], p. 8 (igualmente disponible en http://www.uclm.es/ cesco/investigacion/2008/3.pdf, fecha de visita el 5.7.08).

21 Y es que se ha de tener presente que el convenio de sometimiento a AC puede quedar formalizado expresamente a través de cuatro vías distintas. En particular, las dos específicas y tradicionales, tienen lugar cuando la solicitud de arbitraje coincide con el ámbito de la 


\section{(3.2.) ARBITRAJE INSTITUCIONAL O ADMINISTRADO}

Corresponde a determinadas instituciones, a saber, las juntas arbitrales de consumo (sean de ámbito municipal, de mancomunidad de municipios, provincial, autonómico o estatal ${ }^{22}$ ), la gestión del mismo (arts. 5.1 y 6.j) RD); juntas arbitrales, de carácter permanente, que se consideran dependientes de la Administración Pública a la que están adscritas y que se han de distinguir de los concretos órganos arbitrales, designados ad hoc por el presidente de aquellas y a quienes corresponde resolver los particulares litigios (arts. 21.1.1 ${ }^{\circ}$ y $18.1 \mathrm{RD}$ ).

\section{(3.3.) UNIDIRECCIONALIDAD}

Solo los consumidores o usuarios (no los empresarios o profesionales) pueden instar la puesta en marcha o activar el arbitraje de consumo. Así, según el art. 57.1 TR, a través del sistema arbitral de consumo "se resuelven las reclamaciones de los consumidores y usuarios" (nótese que no dice de los empresarios o profesionales); $y$, aunque el nuevo RD haya decidido guardar silencio al respecto y no concretar la procedencia o a quién corresponde la iniciación del AC, de su posterior regulación se evidencia el mantenimiento de la aludida característica ${ }^{23}$.

Ahora bien, ha de repararse que no obsta tal característica para que posteriormente el empresario o profesional decida reconvenir en el seno del procedimiento arbitral de consumo "en cualquier momento antes de la finalización del trámite de audiencia” (art. 41.1 RD).

oferta pública (art. 24.2 RD) o por la expresa aceptación del reclamado en los restantes casos (art. $24.4 \mathrm{RD}$ ). Otras dos vías, propias de todo convenio arbitral, consisten en una cláusula incorporada a un contrato principal y en un convenio pactado como documento o documentos independientes (art. 24.1 RD). Vías expresas a las que ha de añadirse la tácita introducida ex novo por el $\mathrm{RD}$, en virtud de la cual "se entenderá válidamente formalizado el convenio arbitral por la mera presentación de la solicitud si consta acreditado que esta se formaliza durante el tiempo en el que la empresa o profesional utiliza el distintivo público de adhesión al Sistema Arbitral de Consumo, aun cuando carezca del derecho a tal uso conforme a lo previsto en esta norma" (art. 24.3 RD).

22 Aunque estos son los ámbitos territoriales a que aludía el anterior RD 636/1993, de 3 de mayo, regulador del arbitraje de consumo (art. 3.2) y, en este sentido, ajustándose al mismo existen juntas arbitrales de estos ámbitos, lo cierto es que el actual RD no precisa los ámbitos, limitándose a establecer que son juntas arbitrales, además de la Junta Arbitral Nacional, "las juntas arbitrales territoriales constituidas mediante convenio de colaboración entre las Administraciones públicas y el Instituto Nacional del Consumo, en el que podrá preverse la constitución de delegaciones de la Junta Arbitral territorial, ya sean territoriales o sectoriales" (art. 5.2 RD).

23 Así, por ejemplo, basta con observar que todo arbitraje de consumo comienza con una solicitud presentada por el consumidor (art. $34 \mathrm{RD}$ ). 


\section{(3.4.) GRATUIDAD}

Esta característica, reconocida en el art. 41.1 RD, se traduce en que en principio el procedimiento es gratuito para ambas partes, con la salvedad de "los gastos ocasionados por las pruebas practicadas a instancia de parte", que como regla general "serán sufragados por quien las haya propuesto y las comunes o coincidentes por mitad. Las pruebas propuestas de oficio por el órgano arbitral, serán costeadas por la junta arbitral de consumo o por la Administración de la que dependa, en función de sus disponibilidades presupuestarias" (art. 45.3.1 $\mathrm{RD}$ ). Y decimos que "como regla general" porque, como añade el $2^{\circ}$ párrafo de igual precepto "en el supuesto de que el órgano arbitral aprecie en el laudo, mala fe o temeridad, podrá distribuir los gastos ocasionados por la práctica de las pruebas en distinta forma a la prevista en el párrafo anterior".

\section{(3.5.) EQUIDAD}

En cumplimiento de la confusa Disposición Adicional Única de la $\mathrm{LA}^{24}$, el RD postula en su art. 21, rubricado "normas aplicables a la solución del litigio", que "el arbitraje de consumo se decidirá en equidad, salvo que las partes opten expresamente por la decisión en derecho" (apartado 1). $\mathrm{Y}$, por otro lado, considerando que igualmente el propio RD posibilita a los empresarios o profesionales adherirse al sistema arbitral de consumo en derecho, esto es, expresar "si se opta por que el arbitraje se resuelva en derecho o en equidad" (art. 25.1.2 ${ }^{\circ} \mathrm{RD}$ ), también soluciona cómo se ha de proceder en aquellos casos en que, estando el reclamado adherido en derecho, el consumidor o usuario no ha hecho constar en su solicitud "si presta su conformidad a que se resuelva en esta forma" (extremo que, según el art. 34.1.f), debe constar en toda solicitud de AC). Y la solución pasa, como indica el art. $34.2 \mathrm{RD}$, porque "se comunicará este hecho al reclamante para que manifieste su conformidad con la decisión en derecho. En caso de no estar de acuerdo, se tratará la solicitud como si fuera dirigida a una empresa no adherida" (art. 33.1.2० RD).

Ha de quedar claro que equidad no equivale a arbitrariedad, sino resolución según el leal saber y entender del órgano arbitral, con base en motivos que no necesariamente han de ser jurídicos (aunque pueden serlo), permitiendo sopesar una serie de elementos subjetivos o del caso concreto que, en no pocas ocasiones, escapan de la Ley al establecer esta

24 Decimos "confusa" por posibilitar que en un futuro la normativa reguladora del arbitraje de consumo estableciera la regla de la equidad, descuidando el entonces vigente RD 636/1993, regulador del sistema arbitral de consumo. 
criterios y soluciones generales ${ }^{25}$. De ahí que, en íntima relación, el art. 33.2 RD haya dispuesto que "las normas jurídicas aplicables y las estipulaciones del contrato servirán de apoyo a la decisión en equidad que, en todo caso, deberá ser motivada" 26 .

\section{(3.6.) CARÁCTER UNIPERSONAL DEL ÓRGANO ARBITRAL}

En la línea inspiradora del RD de reducir gastos, frente a la tradicional característica del AC de ser conocido y resuelto por un colegio arbitral tripartito (integrado por un árbitro, con la condición de presidente del órgano, representante de la Administración Pública; otro, de las asociaciones de consumidores y usuarios; y otro, de las organizaciones empresariales o profesionales), su art. 19.1 ha pasado a establecer la regla general de que sea un único árbitro el que conozca de los asuntos (estando acreditado al efecto en todo caso el mismo presidente de la junta arbitral de consumo que administra el arbitraje -art. 17.2 in fine-), "cuando las partes asi lo acuerden" (letra a) o "cuando lo acuerde el presidente de la junta arbitral de consumo, siempre que la cuantía de la controversia sea inferior a 300 euros y que la falta de complejidad del asunto asi lo aconseje" (letra b). No obstante, el apartado 2 de igual precepto posibilita a las partes a "oponerse a la designación de un árbitro único, en cuyo caso se procederá a designar un colegio arbitral'.

\section{(3.7.) RAPIDEZ Y EFICACIA}

- Como principal manifestación de esta rapidez, conviene referirse al plazo máximo para dictar laudo que, de conformidad con el art. 49.1.1 ${ }^{\circ} \mathrm{RD}$, será en principio "de seis meses desde el día siguiente al inicio del procedimiento arbitral, pudiendo ser prorrogado por el órgano arbitral mediante decisión motivada, salvo acuerdo en contrario de las partes, por un periodo no superior a dos meses".

- "Carácter vinculante y ejecutivo" del laudo (57.1 TR y $1.2 \mathrm{RD}$ ). Es esta una característica, en virtud de la cual lo decidido en el laudo es obligatorio para las partes y, en caso de incumplimiento, es posible acudir directamente al juez ejecutor y solicitar su cumplimiento sin necesidad de instar un juicio declarativo previo, de la que actualmen-

25 Lara González, Rafael (2005). "La importancia de la participación de los empresarios y de sus entidades representativas en el sistema arbitral de consumo". Aranzadi Civil, núm. 1. Disponible en: www.westlaw.es [fecha de visita 3 de enero de 2007], pp. 1-10, p. 5.

26 Obsérvese que aunque, como hemos dicho, en el AC los árbitros pueden tener en cuenta y resolver con base en normas jurídicas vigentes, tal y como expresamente establecía la normativa proyectada del $\mathrm{RD}$, este, a nuestro entender de forma inapropiada, parece haber convertido en obligación dicha potestad, al haber sustituido el tiempo verbal de carácter potestativo empleado por aquella normativa ("podrán servir") por el imperativo "servirán". 
te carecen el resto de $A D R$, que también contribuye a la mayor eficacia del AC.

- También la introducción ex novo del AC electrónico, definido como aquel que "se sustancia integramente, desde la solicitud de arbitraje hasta la terminación del procedimiento, incluidas las notificaciones, por medios electrónicos, sin perjuicio de que alguna actuación arbitral deba practicarse por medios tradicionales" (art. 51.1.10 RD), refuerza la rapidez y eficacia propias de esta vía de resolución de conflictos.

- Asimismo, se presenta como novedad trascendental, la introducción del AC colectivo, que "tiene por objeto resolver en un único procedimiento arbitral de consumo los conflictos que, en base al mismo presupuesto fáctico, hayan podido lesionar los intereses colectivos de los consumidores y usuarios, afectando a un número determinado o determinable de estos" (art. $56 \mathrm{RD})$. Si bien es cierto que, considerando el trámite previsto de llamamiento a los afectados durante el plazo de dos meses (art. 59.2 RD) y que es a partir de la finalización de los mismos cuando se inicia el cómputo del plazo para dictar laudo (art. $62 \mathrm{RD}$ ), se puede acabar afectando negativamente la celeridad del AC.

- También parece que el haber posibilitado el RD un recurso ante la Comisión de las Juntas Arbitrales de Consumo (arts. 11.1 y 36.1) contra ciertas resoluciones del presidente de la junta arbitral (en concreto, las que admiten o inadmiten una solicitud de AC con base en las causas indicadas en el art. 2, esto es, por versar o no sobre materias susceptibles de AC -art. 36.1-) puede acabar afectando o incidiendo sobre la rapidez negativamente, en la medida en que implica una dilatación en el tiempo de los AC. Nótese que tal recurso puede ser interpuesto "en el plazo de 15 dias desde la notificación del acuerdo que se impugna" (art. 36.1 in fine) y que la citada Comisión dispone de un plazo de hasta tres meses para resolver el recurso desde su interposición (art. 36.3). Si bien creemos que la previsión del recurso en sacrificio de una mayor celeridad puede estar justificada en caso de inadmisión de solicitudes para garantizar el derecho fundamental a la tutela judicial efectiva, no así cuando se admitan ${ }^{27}$.

\section{(3.8.) “AUSENCIA DE FORMALIDADES ESPECIALES"}

Aunque el RD declara la aplicación supletoria de la LA en todo lo no previsto por él (art. 3.1), contempla ciertas especialidades procedimentales propias, acordes o coherentes con los rasgos esenciales de este

27 Para más detalles, véase nuestra obra Marcos Francisco, Diana (2008). "Nueva perspectiva del arbitraje de consumo a la luz del Real Decreto 231/2008, de 15 de febrero, regulador del Sistema Arbitral de Consumo". Revista General de Derecho Procesal, núm. 16. Disponible en www.iustel.com [fecha de visita noviembre de 2008], pp. 1-58, pp. 54 a 57. 
específico arbitraje. De hecho, el propio RD dedica el Capítulo IV a regular el "procedimiento arbitral" (arts. 33 a 50). Entre ellas cabe citar, por ejemplo, el momento en que se fija el inicio del procedimiento (art. 37), el modo de designación de los árbitros (art. 39.1), la posibilidad de que el empresario reconvenga o el consumidor modifique sus pretensiones en cualquier momento durante el procedimiento hasta antes de finalizar el trámite de audiencia (art. 43), dicho trámite de audiencia a las partes regulada en el art. 44 o los efectos de la incomparecencia de las partes (art. 46).

Pero tales especialidades no deben llevar a pensar que aportan una excesiva rigidez o complejidad a los AC. La misma dependerá del conflicto en cuestión, siendo normal en la práctica que el procedimiento quede reducido a una audiencia (la regulada en el art. $44 \mathrm{RD}$ ), a la que las partes suelen asistir por sí mismas sin postulación procesal y con las alegaciones y pruebas que estiman oportunas en defensa de sus derechos. En cualquier caso, atendidas las especialidades procedimentales previstas por el RD y en comparación con el proceso judicial, no hay duda de que estamos ante un arbitraje "sin formalidades especiales" (art. 57.1 TR).

\section{LA MEDIACIÓN Y CONCILIACIÓN EN EL SISTEMA ARBITRAL DE CONSUMO}

Sin perjuicio de que la mediación o conciliación son ADR que pueden presentarse de forma independiente, esto es, al margen del sistema arbitral de consumo, también es posible que se articulen en su seno. Estamos ante instituciones cuya diferencia fundamental radica en el grado de intensidad de intervención del tercero, de modo que mientras "en la conciliación el tercero pretende que las partes alcancen el acuerdo entre ellas pero no se adoptan medidas persuasivas, integradoras e incluso disuasorias que tiendan a concretar y, en su caso, posibilitar una solución de consenso entre ellas; por su parte, la mediación implica la utilización de estas técnicas expuestas y la facultad de persuasión con el fin de proyectar en un procedimiento en muchos casos más lento la participación activa de las partes en la búsqueda de la solución que, desde la cesión de intereses contrapuestos, lleve a una posición común que, en todo caso, implique una desaparición, o cuanto menos suavización, de la crispación existente" 28 .

28 Barona Vilar, Silvia (1999). Solución extrajurisdiccional de conflictos: Alternative Disputes Resolution (ADR) y Derecho Procesal. Valencia: Tirant lo Blanch, 309 pp., p 81. 


\section{(4.1.) La MEdiación EN El Real DeCRETo 231/2008, DE 15 DE FEBRERO, REGULADOR DEL SISTEMA ARBITRAL DE CONSUMO}

A pesar de la denominación del RD 231/2008, tal norma, acorde con la reunión número 22 del 11 de julio de 2006 de la Conferencia Sectorial de Consumo y el Marco Común de actuación en materia de consumo en ella aprobado para el cuatrienio 2006-200929, también regula la mediación (esta es la excepción de norma estatal a la que supra nos referíamos), aunque muy escuetamente, justificando la ausencia de regulación de este instituto de resolución de conflictos, como indica la EM del RD, en la "congruencia con las competencias autonómicas sobre la materia" 30 . Y de ahí que la mediación se ha de regir "por la legislación sobre la materia que resulte de aplicación" (art. 38.2 RD). No se puede perder de vista que las Comunidades Autónomas han asumido plenas competencias en materia de mediación de consumo ${ }^{31}$, lo que impide al Estado una regulación sistemática y detallada de la misma ${ }^{32}$.

En concreto, el RD dedica ad hoc un solo precepto (art. 38, sobre "mediación en el procedimiento arbitral"), sin perjuicio de hacer sobre la misma algunas consideraciones aisladas a lo largo de su articulado (en particular, los arts. 6.f) y k), 22.1, 25.1.2, $37.3 . \mathrm{a}) .2^{\circ} \mathrm{y}$ b). $1^{\circ}$ y $3^{\circ}, 41.2 \mathrm{y}$ $\left.49.1 .2^{\circ}\right)^{33}$.

29 Como bien indica Busto Lago, "entre los objetivos que se persiguen en dicho Acuerdo se encuentra precisamente el fomento, la difusión y la mejora de los sistemas extrajudiciales de solución de conflictos de consumo, para lo cual se propone como actividad que debe llevarse a cabo la armonización de los criterios aplicables a la mediación con el fin de garantizar la independencia e imparcialidad de los procedimientos. En el ámbito normativo, este Marco Común de Actuación propone la regulación de la mediación de consumo, y su impulso" (véase, Busto Lago, José Manuel (2008). "Mecanismos extrajudiciales de resolución de conflictos de consumo". Disponible en: http://www.uclm.es/actividades0809/cursos/edc/ docs/JoseManuelBusto_4.pdf [fecha de visita agosto de 2009], p. 5).

30 E igualmente reitera la p. 5 de la Memoria Sistema Arbitral de Consumo de 2007 elaborada por el Instituto Nacional del Consumo, disponible en: http://www.consumo-inc.es/Arbitraje/docs/memarb072.pdf, [fecha de visita 13 de octubre de 2008].

31 Bonachera Villegas, Raquel (2008). "El Real Decreto 231/2008, la anhelada modificación del sistema arbitral de consumo". Diario La Ley, núm. 7045. Disponible en: diariolaley.es, consultada [fecha de visita octubre de 2008], pp. 1-22, p. 2.

32 Para más información al respecto, véase Marín López, Manuel Jesús (2007). "Consumidores y medios alternativos de resolución de conflictos". Anuario de la Facultad de Derecho de la Universidad Autónoma de Madrid, núm. 11, pp. 123-150, pp. 142-146.

33 Pese a ello no han faltado autores defendiendo que hubiera sido pertinente que el nuevo RD hubiese contemplado una mayor regulación de la mediación, tal y como hacía el primer Proyecto de Real Decreto por el que se regula el Sistema Arbitral de Consumo y la Mediación en el Procedimiento Arbitral, indicando cuestiones como la función y formación del mediador y el resultado de la mediación (Blanco Carrasco, Marta (2009). "La alternativa de la mediación en conflictos de consumo: presente y futuro". Anuario Jurídico y Económico Escurialense, pp. 129-152, pp. 144 y 145). 
Corresponde a la junta arbitral de consumo "asegurar el recurso a la mediación previa al conocimiento del conflicto por los órganos arbitrales, salvo que no proceda conforme a lo previsto en el articulo 38" (art. $6 \mathrm{RD}$, letra f) y "proveer de medios y realizar las actuaciones necesarias para el mejor ejercicio de las funciones de los órganos arbitrales $y$, en su caso, de los mediadores" (art. $6 \mathrm{RD}$, letra k). El art. 38 contempla la mediación "cuando no existan causas de inadmisión de la solicitud de arbitraje" como fase previa al arbitraje en sí, salvo - de acuerdo con el apartado $1^{\circ}$ - cuando se haya opuesto expresamente alguna parte o la misma ya se haya intentado sin efecto (en este sentido, el RD contempla la posibilidad de que en la misma oferta pública de adhesión el empresario haga constar, entre otros extremos, el de si acepta la mediación previa al conocimiento del conflicto -art. 25.1.2० $\mathrm{RD}-$ ), pero integrando o dentro del mismo procedimiento arbitral de consumo. Prueba de ello es, además de la propia rúbrica del art. 38, que el convenio arbitral de consumo puede haber quedado formalizado dando lugar al inicio del correspondiente procedimiento arbitral habiendo hecho constar documentalmente las partes su voluntad de intentar una mediación previa (art. 37); como también lo es la previsión del RD sobre la suspensión del plazo para dictar laudo para intentar la mediación previa "por un periodo no superior a un mes desde el acuerdo de iniciación del procedimiento arbitral" (art. 49.1.2. ${ }^{3}{ }^{34}$.

Siguiendo con lo dispuesto en el art. 38, del acuerdo resultante alcanzado debe dejar constancia en acta el secretario de la junta arbitral, indicando "la fecha de inicio y fin de la mediación, asi como del resultado de esta" (apartado 2 in fine). Resultado que tiene valor de un simple acuerdo entre las partes ${ }^{35}$.

Para finalizar con lo establecido en el mencionado art. 38, este contempla los principios mínimos que deben regir la actuación del mediador, a saber, la independencia, imparcialidad y confidencialidad; principios,

En este sentido, Marín López (2008) 18 y 19.

Busto Lago (2008) 7; Blanco Carrasco (2009) 148. Sin embargo, esta misma autora ańade (p. 150) que "si tenemos en cuenta lo establecido para el arbitraje con carácter general, es posible otorgar a este acuerdo una eficacia mayor que la del acta, a través de la homologación arbitral del mismo. Esta homologación es posible gracias a la incorporación de la Ley 60/2003 de arbitraje del artículo 36 que recoge el laudo por acuerdo de las partes. En este caso, las partes pueden solicitar al árbitro que recoja el acuerdo alcanzado en el laudo alcanzado para así otorgarle la misma eficacia que tiene el laudo, es decir, efecto de cosa juzgada y ejecutividad (art. 517.2.2 LEC)".

Podría pensarse que la Directiva 2008/52/CE del Parlamento Europeo y del Consejo, de 21 de mayo de 2008, sobre ciertos aspectos de la mediación en asuntos civiles y mercantiles (Diario Oficial -Serie L- núm. 2136 de 24.5.2008) podría aplicarse a la mediación previa a la que alude el $\mathrm{RD}$, valiéndose esta de la gran ventaja de obtener un acuerdo susceptible de constituir título ejecutivo (véanse los Considerandos 8 y 19 y art. 6). Pero, como la misma dice en su Considerando 11, no debe aplicarse a "los sistemas aplicables a las reclamaciones de consumo". 
los dos primeros, cuyo contenido cabe integrar acudiendo a lo dispuesto en las mencionadas Recomendación de la Comisión 98/257/CE, de 30 de marzo, relativa a los principios aplicables a los órganos responsables de la solución extrajudicial de los litigios en materia de consumo ${ }^{36}$ y Recomendación de la Comisión, de 4 de abril de 2001, sobre los principios aplicables a los órganos extrajudiciales de resolución consensual de litigios en materia de consumo que no cubre la Recomendación 98/257/CE 37 ; y confidencialidad de la información que conozca en el curso del procedimiento arbitral a la que el mediador está obligado a guardar también de conformidad con lo dispuesto en el art. 41.2 RD.

En íntima relación, en principio parece que para respetar tales garantías de independencia e imparcialidad ${ }^{38}$, el apartado $1^{\circ}$ in fine del art.

36 Así, al tratar esta, dispone literalmente que "la independencia del órgano responsable de la toma de la decisión estará asegurada, de forma que se garantice la imparcialidad de su acción.

Cuando la decisión se adopte de forma individual, esta independencia estará garantizada por las medidas siguientes:

- la persona designada tendrá la capacidad, la experiencia y la competencia, en particular en materia jurídica, necesarias para la función,

- la duración del mandato de la persona designada deberá ser suficiente para garantizar la independencia de su acción, sin que esta pueda ser destituida sin motivo justificado,

- cuando la persona designada sea nombrada o remunerada por una asociación profesional o por una empresa, no deberá haber trabajado para dicha asociación profesional, ni para uno de sus miembros, ni para la empresa en cuestión, durante los tres años anteriores a su entrada en funciones.

Cuando la decisión se adopte de forma colegial, la independencia del órgano responsable de ella puede garantizarse mediante la representación paritaria de los consumidores y de los profesionales o por el respeto de los criterios antes enunciados".

37 Dice tal Recomendación que "para garantizar la imparcialidad de un procedimiento, las personas responsables del mismo:

a) serán nombradas por un período de tiempo determinado y no podrán ser destituidas sin causa justificada;

b) no tendrán ningún conflicto de interés aparente o real con ninguna de las partes;

c) facilitarán a ambas partes información sobre su imparcialidad y competencia antes de que comience el procedimiento".

Obsérvese que en las Recomendaciones de la Comisión de 1998 y 2001 arriba citadas, el principio o concepto de la independencia aparece ligado al de imparcialidad y "comporta una necesidad de cumplimiento de la función de forma autónoma, sin posibilidad de intervenciones subjetivas, motivadas por criterios de parcialidad que puedan afectar claramente en el desarrollo de los procedimientos extrajudiciales, y, sobre todo, de la decisión que en los mismos se alcance. Por tanto (...) aglutina bajo esta configuración dos conceptos distintos: la independencia y la imparcialidad" (véase Barona Vilar (2004) 75 y 92).

Véase al respecto Blanco Carrasco (2009) 146 y 147.

38 En puridad, con tal previsión no se trata de salvaguardar la independencia e imparcialidad del árbitro, sino la incompatibilidad de ambas funciones (la del mediador y la del árbitro), para directamente garantizar que no se desvirtúe el sentido de cada una de estas funciones (la de mediar y la de arbitrar); de forma similar a lo que ocurre en el proceso judicial penal en cuanto a que el órgano instructor no puede, a su vez, ser el decisor o que el órgano competente para conocer en primera instancia debe ser diferente al competente para conocer de los recursos (así lo ponía de manifiesto Montero Aroca en su Ponencia "Derecho a un juez independiente e imparcial (art. 47 II Carta de Derechos Fundamentales de la Unión 
22.1 (sobre la "abstención y recusación de los árbitros") RD postula que "no podrán actuar como árbitros quienes hayan intervenido como mediadores en el mismo asunto o en cualquier otro que tuviera relación estrecha con aquel". De modo que, si el mediador pretendiese actuar posteriormente como árbitro, sería causa suficiente para justificar su recusación por las partes de conformidad con lo dispuesto en tal precepto. No así en el caso de que la garantía vulnerada fuera la de la confidencialidad, en cuyo caso cabría exigir la oportuna responsabilidad civil por los perjuicios causados, disciplinaria o, incluso, penal al mediador, pero no su recusación.

\section{(4.2.) LA CONCILIACIÓN EN EL REAL DECRETO 231/2008, DE 15 DE FEBRERO, REgULADOR DEL SISTEMA ARBITRAL DE CONSUMO}

En cuanto a la conciliación, hay que decir que también los arts. 42.1, 49.2, 58.2.1 ${ }^{\circ}$ y $59.2 \mathrm{RD}$ contemplan referencias expresas sobre la misma. Nos hemos referido a las funciones mediadoras en el seno del sistema arbitral de consumo, propias y exclusivas de dichas juntas, que no se ha de confundir con las funciones conciliatorias propias de los órganos arbitrales designados por aquellas. En tal sentido, una vez designado el órgano arbitral, encargado de dirigir el procedimiento arbitral de acuerdo con lo dispuesto en el RD, podrá instar a las partes a la conciliación (art. 42.1). De forma que "si durante las actuaciones arbitrales las partes llegan a un acuerdo que ponga fin, total o parcialmente, al conflicto, el órgano arbitral dará por terminadas las actuaciones con respecto a los puntos acordados, incorporando el acuerdo adoptado al laudo, salvo que aprecie motivos para oponerse" (art. 48.2); laudo que, claro está, a diferencia del acuerdo alcanzado por mediación constituirá, como todo laudo, título ejecutivo. Sin embargo, el laudo conciliatorio presenta una importante singularidad frente al régimen general propio de los adoptados sin tal acuerdo. Así, en sede del plazo para laudar, este se reduce si hay acuerdo sobre todos los aspectos del conflicto, debiendo ser "de quince días desde la adopción del acuerdo" (art. 49.2).

Y, para acabar, hemos de hacer mención a las referencias que el RD contiene sobre conciliación al regular el arbitraje de consumo colectivo ${ }^{39}$. En concreto, alude a la misma al tratar en su art. 58 cómo se ha de proceder una vez acordado por el presidente de la junta arbitral competente el

Europea)", impartida el día 18 de septiembre de 2008 con ocasión del Seminario sobre "La justicia en la Unión Europea. Garantías procesales y derechos fundamentales", celebrado en la Universidad Internacional Menéndez Pelayo de Valencia los días 17 a 19 del mencionado mes. En concreto, véanse las pp. 21 a 32 del material proporcionado sobre aquella).

39 Al respecto puede verse nuestra obra Marcos Francisco, Diana (pendiente de publicación en 2011). "¿Es posible la tutela de intereses colectivos y difusos en el arbitraje de consumo? El arbitraje de consumo colectivo en el Real Decreto 231/2008, de 15 de febrero, regulador del Sistema Arbitral de Consumo". Revista Boliviana de Derecho. 
inicio del AC colectivo para recabar el necesario consentimiento del empresario o profesional demandado sin el cual no cabe tramitar ningún AC colectivo. Literalmente dispone que "adoptado el acuerdo de iniciación de actuaciones, la junta arbitral de consumo requerirá a las empresas o profesionales responsables de los hechos susceptibles de lesionar los derechos e intereses colectivos de los consumidores para que manifestara, en el plazo de 15 dias desde la notificación, si aceptan someter al sistema arbitral de consumo la resolución, en un único procedimiento, de los conflictos con los consumidores $y$ usuarios motivados por tales hechos $y$, en su caso, para que propongan un acuerdo conciliatorio que satisfaga total o parcialmente los derechos de los potenciales consumidores o usuarios afectados" (apartado 2.10); propuesta a la que, de existir, estos deberán poder acceder en el lugar indicado al efecto en el llamamiento a los afectados, que se contempla como trámite a observar en este arbitraje colectivo (art. 59.2 RD).

\section{CONSIDERACIÓN FINAL}

El sistema arbitral de consumo, cuyo establecimiento es competencia exclusiva del Estado, en principio ha sido configurado por el mismo de una manera idónea para dar cumplimiento al art. 51 de la Constitución espańola y crear un procedimiento eficaz para proteger los derechos y legítimos intereses económicos de los consumidores y usuarios. Sus características esenciales (singularmente la gratuidad, ausencia de formalidades especiales y rapidez) y muchas de las medidas introducidas en la nueva regulación contribuyen a la eficacia de este medio extrajurisdiccional de resolución de conflictos, pero también lo ha hecho la adecuada opción del legislador de introducir en el mismo sistema arbitral de consumo otras formas extrajudiciales de resolver el conflicto distintas al arbitraje de consumo en sí, como son la conciliación y, especialmente, la fórmula cada vez más "estrella" de la mediación.

\section{BIBLIOGRAFÍA CITADA}

- Abellán Tolosa, Luis (2005). “El sistema arbitral de consumo”. En Reyes López, Ma José (coordinadora): Derecho privado de consumo. Valencia: Tirant lo Blanch, pp. 575-668.

- Álvarez Alacón, Arturo (1999). El sistema español de arbitraje de consumo. Madrid: Instituto Nacional del Consumo, 254 pp.

- Barona Vilar, Silvia (1999). Solución extrajurisdiccional de conflictos: Alternative Disputes Resolution (ADR) y Derecho Procesal. Valencia: Tirant lo Blanch, 309 pp. 
- Barona Vilar, Silvia (2004). "ADR en materia de consumo en la Unión Europea”. En Ruiz Jiménez, José Ángel (coordinador): Temas actuales de consumo: la resolución de conflictos en materia de consumo. San Sebastián: Instituto Vasco de Derecho Procesal, pp. 63-95.

- Bercovitz Rodríguez-Cano, Alberto (2008). "La experiencia del arbitraje de consumo". En Tomillo Urbina, Jorge (director) y Álvarez Rubio, Julio (coordinador): El futuro de la protección jurídica de los consumidores: actas del I Congreso Euroamericano de Protección Jurídica de los Consumidores, Cizur Menor (Navarra): Aranzadi, pp. 379-388.

- Blanco Carrasco, Marta (2009). "La alternativa de la mediación en conflictos de consumo: presente y futuro". Anuario Jurídico $y$ Económico Escurialense, pp. 129-152.

- Bonachera Villegas, Raquel (2008). "El Real Decreto 231/2008, la anhelada modificación del sistema arbitral de consumo". Diario La Ley, núm. 7045. Disponible en: diariolaley.es, consultada [fecha de visita octubre de 2008], pp. 1-22.

- Busto Lago, José Manuel (2008). "Mecanismos extrajudiciales de resolución de conflictos de consumo". Disponible en: http://www. uclm.es/actividades0809/cursos/edc/docs/JoseManuelBusto_4.pdf [fecha de visita agosto de 2009].

- Cabanillas Múgica, S., (2008). "El Real Decreto Legislativo 1/2007, por el que se aprueba el texto refundido de la Ley General para la Defensa de los Consumidores y Usuarios y otras leyes complementarias". Aranzadi Civil, núm. 1. Disponible en: www.westlaw.es [fecha de visita junio de 2008].

- Casado Cerviño, Alberto (2006). "El arbitraje de consumo". Actualidad Civil, núm. 4, pp. 389-430. Disponible en: http://authn. laley.net/comun/cgi-bin/imprimir_actualidad.pl?http://authn.laley. net/ra_civic/2006/r04c_2006_af_1.html [fecha de visita 3 de enero de 2007].

- Casas Valles, Ramón (1992). “Comentario al art. 31”. En Bercovitz Rodríguez-Cano, Alberto y Salas Hernández, Javier (coordinadores): Comentarios a la Ley General para la Defensa de los Consumidores y Usuarios. Madrid: Civitas, pp. 763-809.

- Chillón Medina, José Ma y Merino Merchán, José Fernando (1991). Tratado de arbitraje privado interno e internacional, Madrid, 653 pp.

- Cuñat Edó, Vicente (1995). "Las juntas arbitrales de consumo". En Perspectiva juridica del arbitraje de consumo: Actas del Seminario "Arbitraje de consumo" (Valencia), Valencia: Generalitat Valenciana, Conselleria de Sanitat i Consum, 201 pp.

- Díaz Alabart, Silvia (1994). "El arbitraje de consumo (RD 636/1993, de 3 de mayo)”. Estudios sobre Consumo, pp. 170-225. 
- Gaspar Lera, Silvia (1998). El ámbito de aplicación del arbitraje. Pamplona: Aranzadi, 315 pp.

- Guillén Caramés, Javier, (2007). "Las competencias de los diferentes entes territoriales en materia de protección de los consumidores". En Parada Vázquez, Ramón y Fernández Rodríguez, Carmen (directores): Las competencias locales, Madrid: Marcial Pons, pp. 347-398.

- Lara González, Rafael (2005). "La importancia de la participación de los empresarios y de sus entidades representativas en el sistema arbitral de consumo". Aranzadi Civil, núm. 1. Disponible en: www. westlaw.es [fecha de visita 3 de enero de 2007], pp. 1-10.

- Marcos Francisco, Diana (2008). "Nueva perspectiva del arbitraje de consumo a la luz del Real Decreto 231/2008, de 15 de febrero, regulador del Sistema Arbitral de Consumo". Revista General de Derecho Procesal, núm. 16. Disponible en www.iustel.com [fecha de visita noviembre de 2008], pp. 1-58.

- Marcos Francisco, Diana (pendiente de publicación en 2011). “Es posible la tutela de intereses colectivos y difusos en el arbitraje de consumo? El arbitraje de consumo colectivo en el Real Decreto 231/2008, de 15 de febrero, regulador del Sistema Arbitral de Consumo". Revista Boliviana de Derecho.

- Marín López, Manuel Jesús (2007). "Consumidores y medios alternativos de resolución de conflictos". Anuario de la Facultad de Derecho de la Universidad Autónoma de Madrid, núm. 11, pp. 123-150.

- Marín López, Manuel Jesús (2008). "La nueva regulación del arbitraje de consumo: el Real Decreto 231/2008, de 15 de febrero". Diario La Ley, núm. 6905. Disponible en: diariolaley.es [fecha de visita junio de 2008].

- Palao Moreno, Guillermo (2004). "Comentario a la Disposición Adicional Única. Arbitrajes de consumo". En Barona Vilar, Silvia (coordinadora): Comentarios a la Ley de Arbitraje (Ley 60/2003, de 23 de diciembre), Thomson-Civitas, pp. 1621-1640.

- Rodríguez Rodríguez, José Luis (2006). Origen, estructura y funcionamiento de las juntas arbitrales de consumo. $1^{\text {a }}$ Edición. San Sebastián: Instituto Vasco de Derecho Procesal, 608 pp.

- Ruiz Jiménez, José Ángel (2007). Análisis crítico del sistema nacional español de arbitraje de consumo, San Sebastián: Instituto Vasco de Derecho Procesal, 479 pp. 